\title{
32 channel DQPSK DWDM-PON for local area network using dispersion compensation fiber
}

\author{
Yousef Fazea $^{1,2 *}$ and Angela Amphawan ${ }^{1}$ \\ ${ }^{1}$ Optical Computing and Research Laboratory, School of Computing, Universiti Utara Malaysia, 06010 Sintok, Kedah, Malaysia \\ ${ }^{2}$ Internetworks research Laboratory, School of Computing, Universiti Utara Malaysia, 06010 Sintok, Kedah, Malaysia
}

\begin{abstract}
In the contest to improving optical channel rates in dense wavelength multiplexing (DWDM) service to realize $40 \mathrm{~Gb} / \mathrm{s}$, different adjustment and coherent detection plans are being investigated. In this paper, we present differential quaternary phase-shift keying (DQPSK) balance for the arrangement of a 32channel DWDM in a Local Area Network (LAN).
\end{abstract}

\section{Introduction}

The media communications industry is hustling to support optical channel rates in dense wavelength multiplexing (DWDM) product and services to 40Gbps and more [1-4]. Legacy infrastructure in Local Area Networks (LANs) has faced genuine difficulties in pleasing to popular cloud infrastructures and the expansion in data traffic due to diverse services such as, triple play services applications which involves video, audio, data and many more bandwidth-intensive applications [4-7]. Capacity-limited routers in LAN will benefit essentially from the expansion to $100 \mathrm{Gbps}$. Nonetheless, 40Gbit/s DWDM deployment in LANs is not a panacea. There are a few difficulties, such as, multivendor interconnectivity, compatibility issues with the current layout, scattering resilience, and cost viability for widespread deployment [8, 9]. The 40Gbit/s DWDM is going to be deployed firstly in core and long-haul networks, which makes it importantly required in optical networking transport $[10,11]$. In order to address this, numerous modulation format and coherent detection schemes are being investigated. For long-haul 100Gbps DWDM, dual polarization quadrature phase shift keying (DP-QPSK) is envisaged to be the standard modulation format.

In this paper, we introduce differential quaternary phase-shift keying (DQPSK) modulation for
DWDM deployment in a LAN. This paper proceed as follows; Section 2 describes the DWDM model and parameters followed by Section 3 where the simulation results are analyzed. Conclusion of this paper is presented in Section 4.

Table 1. Fiber parametrs

\begin{tabular}{|c|c|c|c|c|}
\hline Fiber & $\begin{array}{c}\text { Attenuation. } \\
(\mathrm{dB} / \mathrm{km})\end{array}$ & $\begin{array}{c}\text { Dispersion. } \\
(\mathrm{ps} / \mathrm{km}-\mathrm{nm})\end{array}$ & $\begin{array}{c}\text { Dispersion } \\
\text { slope } \\
(\mathrm{ps} / \mathrm{km}- \\
\left.\mathrm{nm}^{2}\right)\end{array}$ & $\begin{array}{c}\text { Effective } \\
\text { core area } \\
\left(\mu \mathrm{m}^{2}\right)\end{array}$ \\
\hline SMF & 0.2 & 17 & 0.075 & 70 \\
\hline DCF & 0.5 & -85 & -0.3 & 22 \\
\hline
\end{tabular}

Table 2. Parameters Configuration

\begin{tabular}{|c|c|}
\hline Data date & 40Gbit/s \\
\hline Seq. length & 64 \\
\hline Sample per Bit & 256 \\
\hline Wavelength Spacing & $200 \mathrm{GHz}$ \\
\hline Length & $50 \mathrm{Km}$ \\
\hline Power & $7.5 \mathrm{dBm}$ \\
\hline
\end{tabular}

\section{Simulation and Model Description}

* Corresponding author: yosiffz@,internetworks.my 


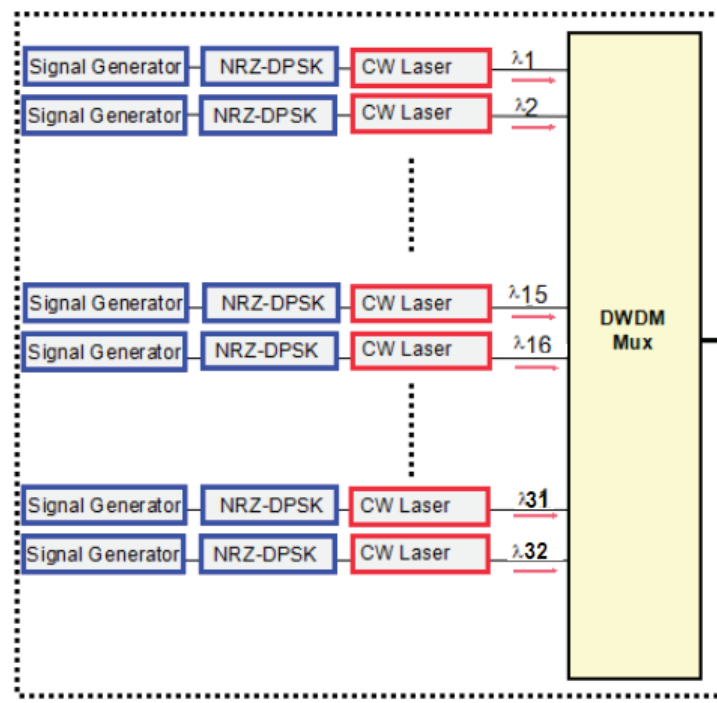

Transmitter

Fig.1. Simulation of 32 channels DWDM-PON

Fig. 1 presents a DQPSK DWDM model in a LAN, simulated using Synopsis OptSim 5.2 [12]. The network maybe divided into three parts, the transmitter, the channel and the receiver. The central frequency is $190 \mathrm{THz}$ with a spacing of $200 \mathrm{GHz}$ and transmitter power of $7.5 \mathrm{dBm}$. The parameters for the optical fiber are given in Table 1 whereas the transmission parameters are presented in Table 2.

\section{Result Analysis and Discussions}

The DWDM model has been evaluated using several metrics measurement as the eye diagram, and optical signal-to-noise ratio (OSNR). The eye opening is proportional to the transmitted time delay, therefore as can be observed in Figure 2, narrow eye-opening result to low propagation delay whereas the OSNR is shown

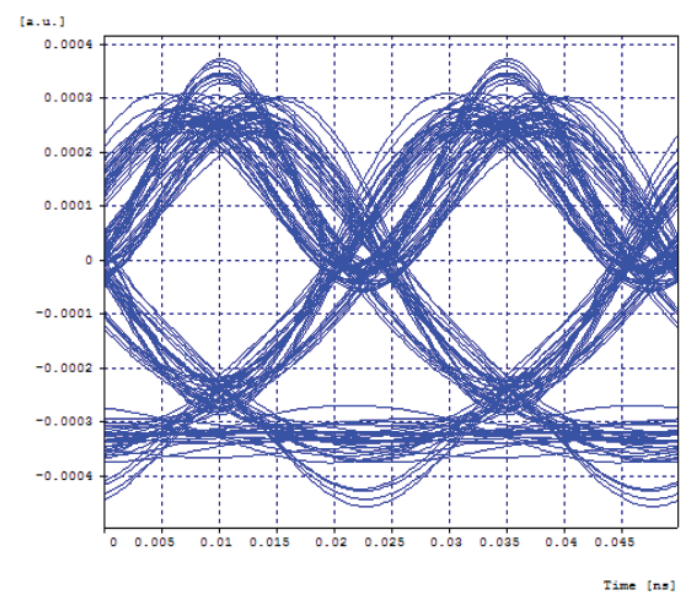

Fig. 2. (a) eye diagram of channel 1

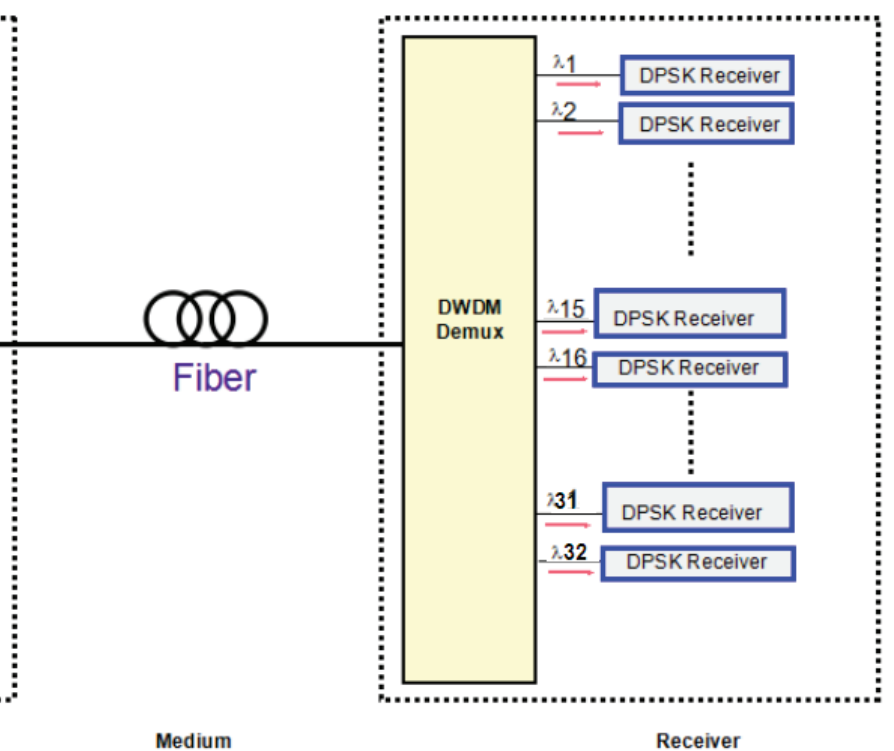

in Figure 3.

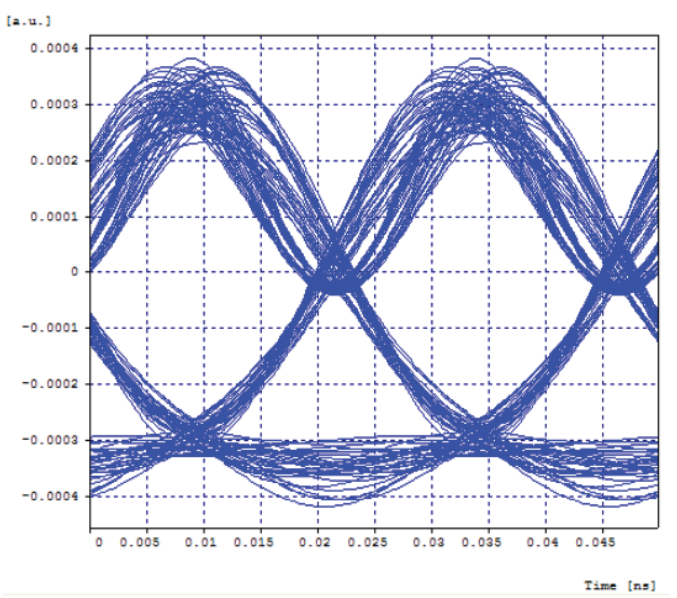

Fig. 2. (b) eye diagram of channel 16

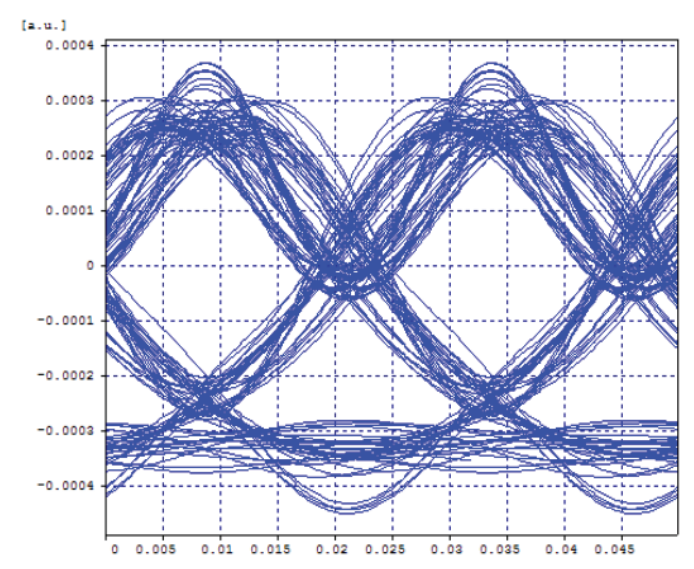

Fig. 2. (c) eye diagram of channel 32 


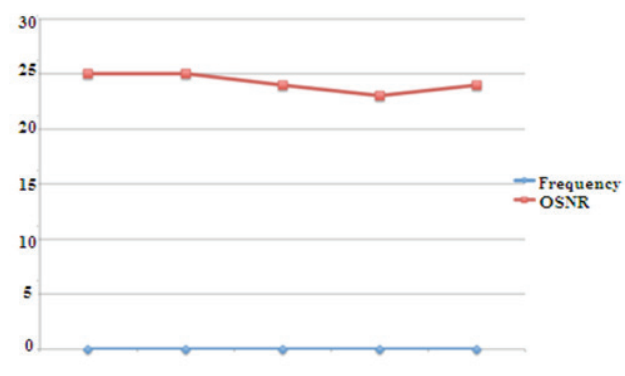

Fig. 3. Frequency and OSNR

\section{Conclusion}

A 40Gbps 32-channel DWDM has been achieved using DQPSK modulation. The DQPSK DWDM system has potential for increasing current capacity-constrained routers in LAN.

\section{References}

1. F. Cavaliere, L. Giorgi, and R. Sabella, Ericsson Review, (2013)

2. Y. Fazea and A. Amphawan, Journal of Optical Communications, vol. 36, pp. 327-333 (2015)

3. Y. Fazea, A. Amphawan, and H. Abualrejal, Advanced Science Letters (2016)

4. A. Amphawan and Y. Fazea, Journal of the European Optical Society-Rapid publications, vol. 11 (2016)
5. S.-J. Park, C.-H. Lee, K.-T. Jeong, H.-J. Park, J.-G. Ahn, and K.-H. Song, Journal of Lightwave Technology, 22, p. 2582 (2004)

6. J.-P. Elbers, Optical Fiber Communication (OFC), collocated National Fiber Optic Engineers Conference, 2010 Conference on (OFC/NFOEC), 2010, pp. 1-3 (2010)

7. F. Council and F. Penetration, Status North America, (2011)

8. D. Fritzsche, D. Breuer, A. Ehrhardt, J. Yeh, Z. Zhang, and W. I. Way, National Fiber Optic Engineers Conference, 2009, p. NWD4 (2009)

9. J. Choi, M. Yoo, and B. Mukherjee, Journal of Optical Communications and Networking, 2, pp. 38-50 (2010)

10. G.-K. Chang, A. Chowdhury, Z. Jia, H.-C. Chien, M.-F. Huang, J. Yu, et al., Journal of Optical Communications and Networking, 1, pp. C35-C50, (2009)

11. Y. Ma, Y. Qian, G. Peng, X. Zhou, X. Wang, J. Yu, et al., Optical Fiber Communication Conference, 2012, p. PDP5D. 7 (2012)

12. I. Rsoft Design Group, OptSim User Guide (2010) 